\title{
O minotauro: ausências e substituições em lobato
}

Daniella Amaral Tavares ${ }^{1}$

RESUMO: Em 1939, Monteiro Lobato publica O Minotauro, uma releitura do mito grego do monstro meio homem, meio touro, morto pelo herói ateniense Teseu. O monstro lobatiano está só em seu labirinto, para onde leva a cozinheira Tia Nastácia. Sua morada na ilha de Creta não contém os jovens atenienses que deveriam ser devorados, nem a violência presente nas narrativas clássicas. No lugar de Ariadne e seu novelo, há Emília e seus carretéis. Ao invés da morte pelas mãos de Teseu, sua derrota pelos bolinhos de Tia Nastácia. Essas operações de supressões e acréscimos são o fio condutor deste estudo sobre os diálogos entre a versão de Lobato e o texto-fonte sobre o Minotauro, cujas origens perdem-se no tempo. Podemos aventar que as escolhas narrativas do autor se baseiam nas suas próprias convicções sobre o processo de reescritura, sobre a adequação do texto ao público-alvo, bem como incluem a valorização da inteligência em detrimento da violência. Para fundamentar nossa análise, tomamos como balizadores, além dos próprios textos de Lobato, reflexões contemporâneas, especialmente de autores como Martins, Hutcheon, Arrojo, Samoyault e Sant’Anna, que versam sobre o processo da adaptação e mecanismos intertextuais nele envolvidos. PALAVRAS-CHAVE: Adaptação literária, mitologia grega, Monteiro Lobato.

ABSTRACT: In 1939, Monteiro Lobato published O Minotauro (The Minotaur), an interpretation of the Greek myth featuring a creature that had the head of a bull and the body of a human being that was killed by the Athenian hero Theseus. Lobato's monster is alone in his labyrinth to where he takes he cook,Tia Nastacia, whom he kidnapped. His home at the Island of Crete neither holds young Athenians to be devoured nor displays the typical violence of the classical tales. Ariadne's ball of thread is replaced by Emilia's bobbins. Instead of being killed by Theseus, the Minotaur is defeated by Tia Nastacia's fried dumplings. Those suppressing and adding operations are the conducting line of our essay about the connection between Lobato's version and the Minotaur's source text, whose actual origin has been lost in time. We are able to argue that Lobato's choices depend on his own beliefs about the writing process, on the need for the adaptation of the material to his targeted readers enhancing, on the one hand, the importance of intelligence which prevails over violence. In order to support our analysis, we have taken into consideration not only Lobato's texts, but also contemporary authors, such Martins, Hutcheon, Arrojo, Samoyault and Sant'Anna, who deal with the adaptation process and the inter-textual mechanisms involved in it.

KEYWORDS: Literary adaptation;Greek mythology; Monteiro Lobato.

A mitologia grega tem sido, ao longo da história da literatura ocidental, uma importante referência, tanto por seu caráter mágico, quanto por seu conteúdo moralizante. Este papel foi especialmente importante para o autor paulista José Bento Monteiro Lobato (1882-1948), que buscou, em sua obra infantojuvenil, não apenas entreter o público, mas também participar de sua formação.

Publicado em 1939, O Minotauro de Lobato se insere no universo literário do Sítio do Picapau Amarelo - um lugar cujos habitantes convivem com naturalidade e humor com personagens tão diversos quanto separados pelo tempo, como Branca de Neve, Pequeno Polegar, Dom Quixote, além de monstros mitológicos e astros de Hollywood.

\footnotetext{
I Mestranda na Universidade Federal da Bahia - Salvador. Contato: amaraldaniella@gmail.com.
} 
Para o autor, essa fusão de elementos, que também incluía a mitologia brasileira, era uma parte importante da sua proposta de entreter e instruir o público jovem, ávido por narrativas com linguagem e formatos adequados ao seu tempo.

Conforme mencionado, Lobato, que mesclara de modo inusitado ao universo rural do Sítio "[...] tanto personagens fundadores da literatura infantil ocidental [...] como personagens da literatura infantil estrangeira contemporânea sua como Alice e Peter Pan [...]" (LAJOLO, 2000, p. 62), acrescenta a este recurso, o uso de uma linguagem coloquial, direta e próxima da narrativa oral - um traço que, segundo Nelly Novaes Coelho, denota a preocupação do autor com uso de uma "[...] linguagem brasileira liberta do magistério lusitano" (2010, p.247-248, grifos da autora).

Na busca por inovações, que podem ser percebidas em toda a produção infantojuvenil lobatiana, bem como nas cartas ao amigo Godofredo Rangel, nota-se um forte desejo de conferir às narrativas canônicas um tom que o autor julgava mais adequado ao seu público e aos seus propósitos pessoais e profissionais, já que ele também exercia as atividades de editor e tradutor:

\footnotetext{
As fábulas em português que conheço, em geral traduções de La Fontaine, são pequenas moitas de amora-do-mato - espinhentas e impenetráveis. Que é que nossas crianças podem ler? Não vejo nada [...] É de tal pobreza e tão besta a nossa literatura infantil que nada acho para a iniciação dos meus filhos. (LOBATO, 2010, p. 370)
}

Deste modo, ao adaptar o mito do Minotauro para o seu público, Lobato realiza diversas interferências, a fim de não somente integrar os personagens do Sítio a esta narrativa clássica, mas também aproximar-se dos seus leitores através do humor, da paródia e de artifícios que os estimulam a buscar, a partir de $O$ Minotauro, muitas outras narrativas - lobatianas ou não, contemporâneas ou clássicas.

Considerando aqui a versão mais corrente do mito do Minotauro como texto-fonte para a adaptação de Lobato, analisaremos o texto do autor em $O$ Minotauro, sob a perspectiva dos estudos contemporâneos da adaptação, com sua postura não hierarquizante ou atrelada à noção de fidelidade ao texto de partida - uma atitude que o próprio autor paulista já anunciava: "Tomei de La Fontaine o enredo e vesti-o à minha moda, ao sabor do meu capricho, crente como sou de que o capricho é o melhor dos figurinos" (LOBATO, 2010, p. 436).

Na análise aqui proposta, pretendemos estudar as supressões, bem como as transformações efetuadas por Lobato no diálogo de sua obra com a narrativa mitológica. Para isso, tomaremos por base, além de textos do próprio autor, reflexões mais contemporâneas que envolvem o processo de adaptação e os mecanismos intertextuais que identificamos no texto de 1939.

\section{Diálogos entre o Minotauro mítico e O Minotauro de Lobato}

Falar da adaptação do mito do Minotauro para o universo infantil é falar da releitura de uma narrativa cujas origens perdem-se no tempo e que não resultam de um texto fundador, mas da compilação de informações transmitidas oralmente e modifica-
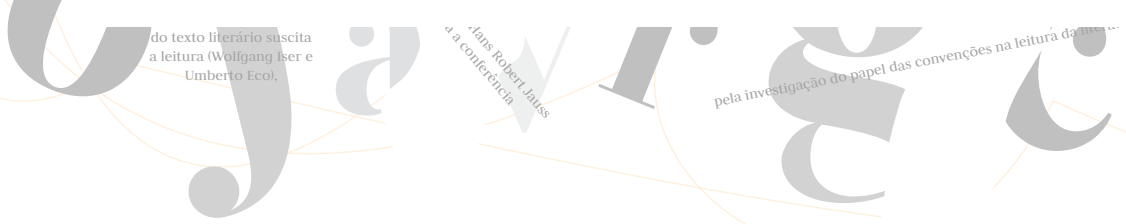
das segundo a vontade dos seus narradores, cujos nomes, em sua maioria, não constam em registros conhecidos, mas cujas histórias ecoam em Homero, Eurípedes e mais fortemente em autores como Catulo, Ovídio e Plutarco.

Percebe-se que o Minotauro e outros personagens associados ao mito, como $\mathrm{Te}^{-}$ seu, Ariadne, Dédalo e Ícaro, exerceram grande fascínio sobre a imaginação ocidental, tendo suas histórias servido de substrato para inúmeras reescrituras na literatura, teatro, cinema e artes plásticas - conforme afirma Samoyault: “[...] o mito dissolve [...] sua própria origem na multiplicidade de suas versões" (2008, p. 115).

Assim, diante da impossibilidade de utilizarmos um texto fundador sobre o mito do Minotauro, trabalharemos com um resumo extraído do autor grego Plutarco (46 - 126 d. C.), em sua obra Vidas Paralelas, aqui estudada a partir do primeiro volume da série editada em 1991, pela Paumape.

A versão mais corrente do mito do Minotauro, presente em uma das narrativas de Plutarco (1991, p. 28-34), conta a história de um ser híbrido, meio homem meio touro, alimentado exclusivamente de carne humana e aprisionado desde o seu nascimento, por ordem do rei Minos, num labirinto construído pelo arquiteto Dédalo. A cada nove anos, o rei cretense exigia que a cidade de Atenas lhe enviasse, como tributo pela morte do príncipe Androgeu, sete rapazes e sete moças que seriam devorados pelo Minotauro. Na época do pagamento do terceiro tributo, Teseu, príncipe e herói ateniense, partiu para Creta, sob a orientação do Oráculo de Delfos, para derrotar o Minotauro. Guiado por um novelo dado por Ariadne, filha de Minos, ele consegue entrar no labirinto, matar o monstro e sair de lá para, em seguida, fugir com a princesa, que é abandonada na ilha de Naxos, onde é encontrada pelo deus Dionísio, com quem se casa.

Em Lobato, O Minotauro começa com a menção ao desaparecimento da cozinheira Tia Nastácia, supostamente sequestrada por algum monstro no final de um livro anterior - $O$ Picapau Amarelo (1939). Ali, um bando de monstros mitológicos invade as terras do Sítio do Picapau Amarelo, enfurecidos por não terem sido convidados para o casamento do príncipe Codadade, das Mil e Uma Noites, com Branca de Neve. Em meio à confusão formada, Tia Nastácia, que comandava a preparação de um imenso banquete, desaparece, para a tristeza de Dona Benta, Narizinho e do Visconde de Sabugosa (LOBATO, 1965d, p. 181-188).

Com a decisão de resgatá-la, os personagens do sítio retrocedem no tempo até chegarem à Atenas de Péricles, onde permanecem Dona Benta e Narizinho, enquanto Pedrinho, Emília e Visconde "mergulham" ainda mais fundo, até a época da "Grécia Heróica", onde acreditam estar Tia Nastácia. Após muitas aventuras e encontros com personagens e deuses mitológicos, a cozinheira é encontrada com a ajuda do Oráculo de Delfos e tirada, sem dificuldades, do labirinto de um obeso e apático Minotauro.

É interessante apontar que a versão lobatiana para o mito do Minotauro coloca em evidência apenas um personagem da versão canônica: o próprio Minotauro, cujo covil não abriga mais um monstro devorador de seres humanos, mas um glutão, engordado e vencido pelos bolinhos de Tia Nastácia. Aqui, Teseu e Minos, citados de modo sucinto

Para Lobato, este seria o tempo em que a Grécia era “[...] uma coleção de reinos, de tribos em luta, de famílias poderosas; o tempo da guerra de Tróia que Homero descreve na Ilíada; e o tempo dos heróis tebanos, da viagem dos Argonautas, dos monstros fabulosos, como a Hidra de Lerna e outros" (LOBATO, 1965e, p. 12).
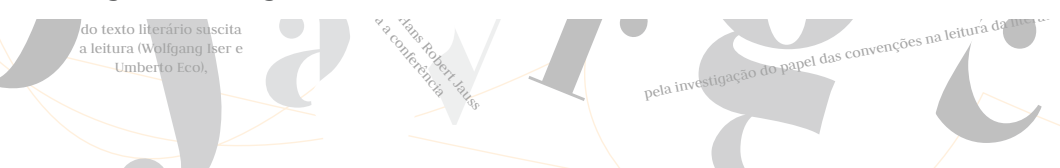
(LOBATO, 1965e, p.106), talvez como uma alusão ao texto-base, não estão presentes nos acontecimentos vividos pelos "picapaus".3 na Ilha de Creta. Os jovens atenienses, que seriam ali devorados, também estão ausentes e não são mencionados, assim como os personagens Dédalo, Ariadne e Dionísio.

Observamos, portanto, que o trabalho de Lobato se fundamenta na ressignificação dos conteúdos do texto-fonte e não no "transporte" integral de uma narrativa produzida num contexto distante para um livro voltado para os jovens brasileiros da primeira metade do século XX.

Em Reinações de Narizinho (1931), o narrador ressalta, de modo irreverente, a importância de transformar uma determinada história em algo mais palatável às crianças brasileiras:

\footnotetext{
- Leia da sua moda, vovó! - pediu Narizinho. A moda de dona Benta ler era boa. Lia “diferente" dos livros. Como quase todos os livros para crianças que há no Brasil são muito sem graça, cheios de termos do tempo do onça ou só usados em Portugal, a boa velha lia traduzindo aquele português de defunto em língua do Brasil de hoje. (LOBATO, 1965a, p. 199)
}

No prefácio à segunda edição das Aventuras de Hans Staden (1927), Lobato comenta que o sucesso de livros de aventura, a exemplo de Robinson Crusoé (1719), se deve às releituras realizadas pelas adaptações:

Quem lê hoje, ou pode ler, o livro de Defoe na forma primitiva em que apareceu? Os eruditos. Também só os eruditos arrostam hoje a leitura do original das aventuras de Staden. Traduzidas ambas, porém, em harmonia moderna, toante com o gosto do momento, emparelham-se em pitoresco, interesse humano e lição de moral. Equivalem-se. Anos atrás tivemos a ideia de extrair do quase incompreensível e indigesto original de Hans Staden esta versão para crianças - e a acolhida que teve a primeira edição, bastante larga, leva-nos a dar a segunda. (LOBATO, 1965b, p. 119)

A preocupação com o público receptor de uma literatura inicialmente produzida em outra língua e outro contexto também é compartilhada pelos estudos de teóricos descritivistas como André Lefevère e Gideon Toury, que, segundo Martins (2002, p. 33), entre outros objetivos, se voltam para os elementos que controlam a produção e a recepção da literatura traduzida.

Em seu artigo sobre os estudos descritivos da tradução, Martins comenta que as intervenções realizadas no processo tradutório, bem como a recepção do seu produto final, estão profundamente associadas a fatores socioculturais (MARTINS, 2002, p.34) uma opinião que se articula com a de Lobato, não somente sobre a tradução de uma determinada obra para o português, mas também acerca da adaptação, para o leitor brasileiro, de um texto produzido numa outra época.

Um exemplo desse posicionamento pode ser identificado no início do livro D. Quixote das crianças (1936), quando Dona Benta declara que irá narrar as aventuras de D.

“Picapaus" é uma maneira utilizada por Monteiro Lobato para se referir aos personagens que vivem no Sítio do Picapau Amarelo.

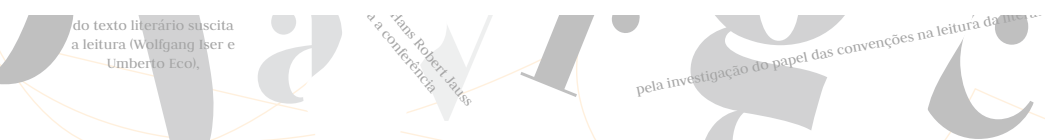


Quixote de forma a ser compreendida por todos. A ideia é recebida com entusiasmo pela boneca Emília: "Isso! - berrou Emília [...] Os viscondes que falem arrevesado lá entre eles. Nós que não somos viscondes nem viscondessas, queremos estilo clara de ovo, bem transparentinho, que não dê trabalho para ser entendido" (LOBATO, 1965c, p. 12).

As necessárias intervenções sobre o texto-base são igualmente levantadas por $\mathrm{Hu}^{-}$ tcheon em Uma Teoria da Adaptação (2011): “Tal como a tradução, a adaptação é uma forma de transcodificação de um sistema de comunicação para outro." (HUTCHEON, 2011, p. 9). A autora caracteriza como procedimento "transcultural" os novos significados inevitavelmente criados a fim de que as histórias sejam mais bem aceitas pelo seu novo público (HUTCHEON, 2011, p. 9-10).

Para dar continuidade à nossa análise, podemos também supor que a versão lobatiana do mito do Minotauro funcionou, metaforicamente, como um palimpsesto no qual um texto foi escrito sobre as marcas deixadas por um outro texto apagado. Na opinião do psicanalista Michel Schneider, os textos literários são produtos de reescrituras sobre textos anteriores, cujas origens se perdem no tempo:

O texto literário é um palimpsesto. O autor antigo escreveu uma “primeira” vez, depois sua escritura foi apagada por algum copista que recobriu a página com um novo texto, e assim por diante. Textos primeiros inexistem tanto quanto as puras cópias; o apagar não é nunca tão acabado que não deixe vestígios, a invenção, nunca tão nova que não se apóie sobre o já-escrito. (SCHNEIDER, 1990, p.71)

Ainda sobre as relações da metáfora da reescritura com o palimpsesto, no caso da adaptação, podemos considerar as afirmações de Rosemary Arrojo: "Metaforicamente [...] o 'palimpsesto' passa a ser o texto que se apaga, em cada comunidade cultural e em cada época, para dar lugar a outra escritura (ou interpretação, ou leitura ou tradução) do 'mesmo' texto." (2007, p. 23-24). Desse modo, a autora nos mostra que o texto não deve ser encarado como algo imutável, mas como ponto de partida para a produção de novos significados em contextos culturais diversos.

Ao reescrever sobre o palimpsesto da narrativa mítica, o autor paulista confere à sua obra não somente um tom mais atrativo aos jovens, mas também coloca as suas próprias convicções no conteúdo de $O$ Minotauro, em cujas páginas é possível encontrar o repúdio de Lobato à brutalidade humana e ao progresso tecnológico.

No terceiro capítulo do referido livro, Dona Benta comenta horrorizada:

As ruas, feitas originariamente para os pedestres, foram invadidas pelas máquinas de correr e de empestar o ar com o fedor da gasolina - máquinas tremendamente destruidoras que fazem mais vítimas num ano do que as fizeram na Grécia Antiga todos os Minotauros e Quimeras. (LOBATO, 1965e, p. 22)

Mais adiante, ao comparar a vida moderna com a da Grécia antiga, idealizada por Lobato, a personagem afirma: "Com as suas invenções constantes, o progresso nos empurra para frente - para delícias e também para mais tumulto, mais aflição, mais corre-
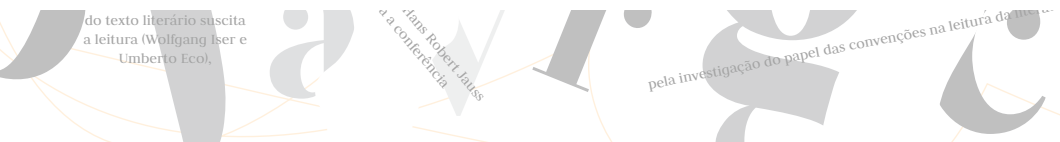
ria, mais pressa [...] mais guerra, mais horror. Essa é a razão da loucura estar tomando conta dos homens" (LOBATO, 1965e, p. 22).

Dona Benta, porta-voz do discurso pacifista lobatiano, assim se refere aos gregos da Atenas de Péricles, sobre o futuro:

\footnotetext{
Por mais que a inteligência se desenvolva, a estupidez não deixa o trono - e as guerras, filhas dessa estupidez, vão sendo cada vez mais terríveis. Eu não quero desiludi-los, meus senhores, porque também não me desiludi totalmente. Mas afirmo que daqui a 2.377 anos Sua Majestade a Estupidez Humana estará mais gorda e forte do que hoje... (LOBATO, 1965e, p. 205-206)
}

Conforme destacamos, podemos também supor que, ao transformar o monstro antropófago num pacato comedor de bolinhos, Lobato não apenas se opõe à violência, mas também marca uma ideia presente em toda a sua obra - a vitória da inteligência sobre a força bruta. Em Os Doze Trabalhos de Hércules (1944), o herói Hércules pondera sobre a questão: "Sim, refletia consigo o herói. Eles representam a Inteligência e eu só disponho da Força. Em muitos casos a Força nada vale e a Inteligência é tudo [...]” (LOBATO, 1965f, p. 152).

Em $O$ Minotauro, ao fazer com que Tia Nastácia, representada como frágil e pouco afeita a aventuras, derrote o monstro por meio de suas artes culinárias, Lobato reafirma o propósito acima mencionado e sinaliza uma mudança no comportamento e nos hábitos alimentares do Minotauro: “Acabou completamente manso. Esqueceu até a mania de comer gente” (LOBATO, 1965e, p. 227).

A substituição, carregada de humor sutil, nos conduz a outra reflexão - o uso da paródia como meio de diálogo com o mito, o que exigirá que, inicialmente, consideremos termos como "dialogismo" e "intertextualidade", a fim de localizarmos a paródia lobatiana como recurso que simultaneamente alude à versão clássica do mito e se desvia dela.

Na análise apresentada por Samoyault, o conceito de dialogismo pensado pelo teórico Mikhail Bakhtin considera o texto como “[...] o lugar de uma troca entre pedaços de enunciados que ele redistribui ou permuta, construindo um texto novo a partir dos anteriores." (SAMOYAULT, 2008, p. 18). Esta visão do texto como um produto do encontro de inúmeros outros textos é desdobrada na noção de intertextualidade, elaborada nos anos 60, por Julia Kristeva, para quem “[...] todo o texto se constrói como um mosaico de citações, todo texto é absorção e transformação de um outro texto.” (KRISTEVA, 1969, p. 145 apud SAMOYAULT, 2008, p. 16).

Ao entendermos $O$ Minotauro como um espaço onde ocorreram múltiplos diálogos com o mito, localizamos a utilização da paródia como principal elemento modificador da versão canônica: “A paródia transforma uma obra precedente, seja para caricaturá-la, seja para reutilizá-la, transpondo-a. Mas qualquer que seja a transformação ou a deformação, ela exibe sempre um liame com a literatura existente" (SAMOYAULT, 2008, p. 53). Para Sant'Anna (2002, p. 12) “[...] a paródia se define através de um jogo intertextual." e "Falar de paródia é falar de intertextualidade das diferenças.” (2002, p. 28, grifo do autor). 
As transformações operadas pela paródia em Lobato utilizam, via de regra, o recurso do humor para marcar a diferença com o texto-fonte. A título de exemplo, tomemos a descrição do monstro de Creta por Plutarco e, em seguida, pelo texto lobatiano.

O autor grego cita Eurípedes, ao definir o Minotauro como "um ser híbrido, uma besta desalmada [...] Mescla da natureza do homem e do touro"(PLUTARCO, 1991, p. 29).

Por sua vez, o narrador lobatiano assim caracteriza a "besta desalmada" de Plutarco:

\footnotetext{
- Mas como está gordo [...]. Muito mais parece aquele célebre cevado que Dona Benta comprou do Elias Turco. Parece que nem pode erguer-se do trono [...] o monstro estava gordíssimo, quase obeso, com três papadas caídas; o seu corpanzil afundava dentro do trono. Que teria acontecido? (LOBATO, 1965e, p. 221).
}

Ao optar pela imagem de um gordo e sonolento Minotauro, Lobato realiza um "desvio total" (SANT’ANNA, 2002, p. 38) sobre a tradicional representação ameaçadora do monstro - o mesmo procedimento de distanciamento vale para a personagem Ariadne e seu novelo salvador, já que ambos são respectivamente substituídos pela boneca Emília e seus carretéis de linha (LOBATO, 1965e, p. 220).

Supomos também que, de forma sutil, o autor paulista construiu um Minotauro mais humano, dispondo de uma cozinha equipada com um grande fogão, frigideiras e os ingredientes necessários para Tia Nastácia preparar seus famosos bolinhos (LOBATO, 1965e, p. 222). Além disso, na medida em que engorda, torna-se tão preguiçoso a ponto de não conseguir mais se levantar de seu trono (LOBATO, 1965e, p. 227).

A “rebeldia” em relação ao texto parodiado (SANT’ANNA, 2002, p. 32) aparece também no episódio do Oráculo de Delfos - em Plutarco, o herói Teseu aconselha-se com o Oráculo antes de partir para Creta: "Pelo que se conta, o deus de Delfos ordenou-lhe por intermédio de um oráculo que tomasse Afrodite como guia e companheira de viagem” (PLUTARCO, 1991, p. 31).

Em O Minotauro, os sacerdotes do santuário de Delfos, após receberem o Visconde de Sabugosa como pagamento pela consulta, conduzem Pedrinho e Emília à sacerdotisa do deus Apolo, intitulada Pítia, que aconselha os visitantes com as palavras que recebe da referida divindade (LOBATO, 1965e, p. 216). Ao revelar a verdade de modo enigmático, Apolo declara: "O trigo venceu a ferocidade do monstro de guampas". (LOBATO, 1965e, p. 217).

Depois de uma breve reflexão sobre o significado das palavras da sacerdotisa, Emília desvenda o paradeiro de Tia Nastácia:

\footnotetext{
- Tudo está claro como água, Pedrinho! “O trigo” quer dizer tia Nastácia, porque ela, como cozinheira, lida muito com trigo, farinha de trigo, massa de trigo, pastéis, bolinhos, etc. E com as coisas gostosas que ela fez com a farinha de trigo "venceu”, isto é, amansou a "ferocidade do monstro de guampas" que não pode ser outro senão o Minotauro. De todos os monstros que invadiram o palácio do Príncipe Codadade só havia um de guampas, ou chifres: o Minotauro. (LOBATO, 1965e, p. 217, grifos do autor)
}

Sobre o trecho destacado, podemos aventar que Lobato não apenas substituiu o conselho do Oráculo sobre a obediência a Afrodite (a deusa do amor) pela indicação do
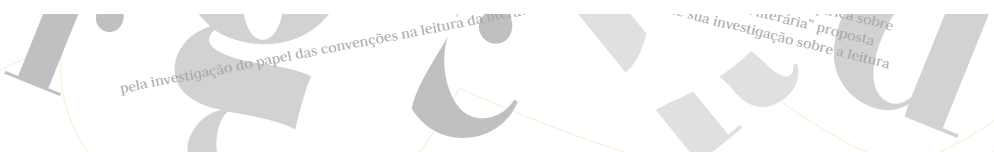
destino de Tia Nastácia, mas também deslocou a vitória de Teseu sobre o Minotauro para as mãos habilidosas da quituteira. Mais uma vez, portanto, verificamos a opção de Lobato em colocar a astúcia no lugar da violência, substituindo uma morte sangrenta por uma derrota pacífica - o Minotauro de Lobato, assim como os mitos que se perpetuam em nossa imaginação, não conhece a morte.

Como adaptador de textos a contextos diversos do Brasil do início do século XX, Lobato não somente assimilou obras do cânone literário ocidental, mas estabeleceu com elas múltiplos diálogos. Ao adaptar o texto de partida do mito do Minotauro, em 1939, Lobato põe em prática diversas ressignificações a fim de aproximar a narrativa clássica do seu jovem público: "A re-escritura do mito não é pois simplesmente repetição de sua história [...] Operações de transformação asseguram a sobrevida do mito e sua contínua passagem [...]" (SAMOYAULT, 2008, p. 117).

À primeira vista, as referências ao mito em $O$ Minotauro parecem escassas. No entanto, conforme ponderamos, o texto mantém seu vínculo com a narrativa-fonte, justamente por meio dos desvios realizados. Com isso, muitos elementos ganham novos significados, como as palavras do Oráculo, a nova forma e o comportamento do monstro, a sua preferência pelos bolinhos no lugar da carne humana, a Ariadne-Emília, o Teseu-Tia Nastácia e a violência substituída pela astúcia e pelo humor.

A releitura operada, uma vez revestida das convicções pacifistas do autor, também realiza as "excisões" mencionadas por Samoyault (2008, p. 117) sobre os "procedimentos de passagem", elencados por Genette - como verificamos, a morte do Minotauro, motivo da aventura de Teseu em Creta, é suprimida do texto Lobato.

Assim, a opção pela preservação da vida, presente em toda a obra infantojuvenil do autor, também aparece posteriormente ao texto $O$ Minotauro, quando os "picapaus" retornam à "Grécia Heróica" em Os Doze Trabalhos de Hércules. Num dado momento da obra, Emília critica os enormes acessos de fúria do herói Hércules, a quem apelidou de "Lelé":

\footnotetext{
Esse seu gênio exaltado não dá certo, Lelé. Por qualquer coisinha fica fora de si, enxerga tudo vermelho e lá vem a hecatombe [...] O bom sistema é o dos americanos nas fitas de cowboys. Quando chega a hora, o pega é tremendo, é dos que fazem a gente se torcer [...] Mas ninguém morre! Era o que você devia fazer aqui [...] Que direito tem uma criatura de tirar a vida de outra - não é mesmo, Visconde?” (LOBATO, 1965f, p. 166)
}

Vale destacar que, em Os Doze Trabalhos de Hércules, Lobato busca, além de substituir a morte pela vida, valorizar os momentos em que o truculento herói modifica o seu comportamento agressivo devido à influência recebida dos "picapaus" - uma transformação, conforme demonstramos aqui, já utilizada em $O$ Minotauro. 


\section{Referências Bibliográficas}

ARROJO, Rosemary. Oficina de tradução: a teoria na prática. 5. ed. São Paulo: Ática, 2007. COELHO, Nelly Novaes. Panorama histórico da literatura infantil/juvenil: das origens indo-européias ao Brasil contemporâneo. 5. ed. São Paulo: Amarilys, 2010.

HUTCHEON, Linda. Uma teoria da adaptação. Tradução André Cechinel. Florianópolis: UFSC, 2011.

LAJOLO, Marisa. Monteiro Lobato: um brasileiro sob medida. São Paulo: Moderna, 2000. LOBATO, Monteiro. Reinações de Narizinho. São Paulo: Brasiliense, 1965a. (Obras completas de Monteiro Lobato, $2^{\mathrm{a}}$ série, Literatura infantil, v. 1).

Caçadas de Pedrinho e Hans Staden. São Paulo: Brasiliense, 1965b. (Obras completas de Monteiro Lobato, $2^{\text {a }}$ série, Literatura infantil, v. 3).

. D. Quixote das crianças. São Paulo: Brasiliense, 1965c. (Obras completas de Monteiro Lobato, $2^{\mathrm{a}}$ série, Literatura infantil, v. 9).

. O Picapau Amarelo e A reforma da natureza. São Paulo: Brasiliense, 1965d. (Obras completas de Monteiro Lobato, $2^{\text {a }}$ série, Literatura infantil, v. 12).

. O Minotauro. São Paulo: Brasiliense, 1965e. (Obras completas de Monteiro Lobato, $2^{\mathrm{a}}$ série, Literatura infantil, v. 13).

. Os doze trabalhos de Hércules. São Paulo: Brasiliense, 1965f. (Obras completas de Monteiro Lobato, $2^{\text {a }}$ série, Literatura infantil, v. 16).

. A Barca de Gleyre. São Paulo: Globo, 2010.

MARTINS, Marcia A. P. Descriptive translation studies: uma revisão crítica. Gragoatá, Niterói, n. 13, p. 33-52, 2o sem. 2002.

PLUTARCO. Vidas Paralelas. São Paulo: Paumape, 1991. v.1.

SAMOYAULT, Tiphaine. A intertextualidade. Trad. Sandra Nitrini. São Paulo: Hucitec, 2008. SANT'ANNA, Affonso Romano de. Paródia, paráfrase e cia. 7. ed. São Paulo: Ática, 2002.

SCHNEIDER, Michel. Ladrões de palavras: ensaio sobre o plágio, a psicanálise e o pensamento. Trad. Luiz Fernando P. N. Franco. Campinas: UNICAMP, 1990.

Artigo ReCEBIDO EM: 31 jul. 2012

ArTigo ACEITO Ev: 12 set. 2012

ReFerênciA ELETrônica: taVARES, Daniella Amaral. O Minotauro: ausências e substituições em Lobato. Revista Criação \& Crítica, n. 9, p. 152-160, nov. 2012. Disponível em: <http://www.revistas.usp.br/ criacaoecritica>. Acesso em dd mmm aaaa.
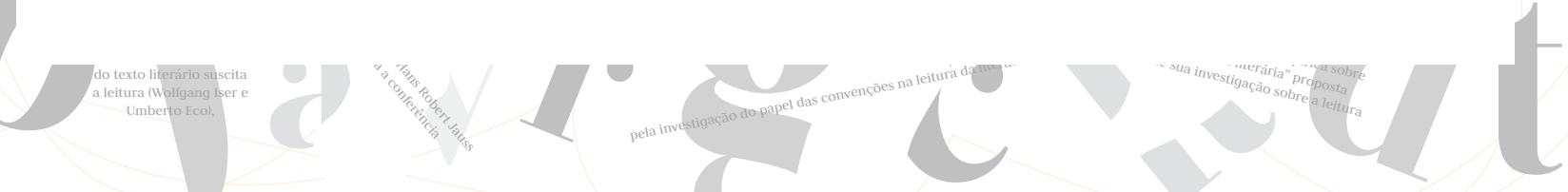